\title{
The main trends in the development of public- private partnership in the field of education in historical retrospective
}

\author{
Natalia Simachkova ${ }^{1, *}$, Oksana Trotsenko ${ }^{1}$, and Sergey Slukin ${ }^{1}$ \\ ${ }^{1}$ Ural State Economic University, 620144, 628 Marta str., Ekaterinburg, Russia
}

\begin{abstract}
The growing interest to public-private partnership (hereinafter PPP) projects in the field of education in the conditions that lead to more intensive social and economic development of Russia is the basis for studying domestic and global historical experience in this issue. The article examines the main trends of the PPP development in education through the prism of historical retrospective. On the basis of the analysis of the historiography and modern scientific opinions in the study of the formation and development of PPP in the field of education, researchers formed their understanding regarding this issue in the historical past and in modern socio-economic space of Russia. The historical analysis allows determining the main milestones in the emergence and further development of various forms of interaction between the state, business and education. The conclusions, to which the authors came, allow identifying the main trends and characteristic features of public-private partnership in the sphere of education. The purpose is to define basic directions of the PPP development through the prism of historical retrospective and analysis of contemporary scientific opinions. Methodology of the work: retrospective, systemic and comparative methods were used in the paper. Results: the research of historical experience in the development of PPP in education in Russia was carried out. The latest scientific opinions regarding this issue were analyzed that allowed identifying current trends in the development of PPP in education.
\end{abstract}

The interaction of the state and business in order to solve socially significant problems has existed for a long time. Initially in Russia such interaction was manifested through the organization of procurements, but lately it has taken a legally binding form of cooperation based on the mechanisms of public-private partnership.

In the Concept of long-term social and economic development of the Russian Federation for the period up to 2020, the development of social services sector on the principles of public-private partnership is indicated as a strategic direction, which can have a positive impact on the quality of economic growth. Global experience shows that the most actively PPP develops in infrastructure sectors, in particular, in the sectors of social infrastructure, which include education. Thus, E.A. Semenova notes that in the most

* Corresponding author: nikolina73@yandex.ru 
developed countries PPP is more often used in education and health care than in any other areas. The reason for this is the need for an active interaction between the state and business when developing and implementing programs and projects aimed at resolving urgent socioeconomic problems [15].

The basic purpose of PPP is the development of infrastructure in the interests of society by integrating resources and experience of each side, implementing socially significant projects at the least cost and risks, providing quality services [14].

Most countries of the world demonstrate interest to the PPP projects. In the Russian Federation, the possibilities of PPP in the sphere of education are not enough used. However, a long-term historical experience of the PPP development in education deserves an attention.

So, for the first time, universities and institutes were opened in Russia after liberal reforms of Alexander the Second and the reforms of S.Yu. Witte, and a wide network of commercial schools appeared. 11 universities were created until 1917, [11, p. 22], which became not only the centers of the development of education and enlightment, but also locomotives of the industrial modernization, and the link between the state, business and society. S.Yu. Witte played a significant role in the promotion of PPP in the sphere of the developing education. His reform led to the emergence of a network of polytechnical institutions and commercial schools, which should have been liable to solve the task of establishing the true PPP in education. S.Yu. Witte's program provided for financial support for the construction and development of universities and technical institutes from the side of local authorities and entrepreneurship [4]. The introduction of educational programs took place with active participation of industrialists and business [10]. Thus, in our view, the formation of the construction "education - business - the state" began to take shape for the first time in Russia that was promising in the conditions of industrial modernization and liberal bourgeois reforms.

The revolution of 1917 fundamentally changed political and socio-economic pattern of the national development. Despite the subsequent civil war, famine, and devastation, the number of educational institutions doubled from 1917 to 1921. But since the "new" power liquidated all basic requirements for educational standards and the evaluation of knowledge, they turned into centers of anarchy and revolutionary propaganda [5, p. 79], and later a large part of them was closed.

The task of establishing a public partnership in the field of education began to be solved in the 1930s under J.V. Stalin, who proposed a key formula for its solution: "each department should become a separate higher educational establishment" and primarily solve the tasks of modernizing the country's economy. In this period, the positions of the socialist sector in industry, agriculture, etc. were strengthened that led to the need in the training of new scientific personnel and qualified specialists, the order on which formed the state. There was no need in a private partnership at that time [5, p. 18].

After the Second World War, new challenges arise in solving the issues of overcoming the post-war devastation, and again training of personnel and getting close cooperation with the recovering industry in the sphere of education came to the fore. In 1959, the Resolution of the Soviet Council of Ministers of the USSR No 1075, dated September 18 "On participation of industrial enterprises, state farms and collective farms in recruiting students for higher education institutions and technical schools, and in training of specialists for their enterprises" was adopted. Thus, industrial enterprises, collective farms and state farms should send their workers to higher educational institutions and technical colleges who have worked for a period of at least two years. They were subjects of the priority enrollment [13]. According to K.T. Galkin, "in the Soviet period education was considered mainly as a condition for the realization of the right of citizens to work" [5, pp. 12, 20], therefore the higher school graduates' employment and their forced work on the state 
enterprises became one of important forms of public partnership in the sphere of education in the Soviet period.

After the collapse of the USSR, in the conditions of transition to the market relations, there was a serious crisis in the education sector. A large number of new educational institutions appear, including private higher educational establishments, aimed not at the creation and development of socio-economic environment of the state, but at formal issuance of diplomas and training of specialists with low professional level [16, p.285]. In this complex transition period, the elements of PPP in the sphere of education just emerged [12, p. 137].

In the 2000s, the situation in the development of the PPP mechanism in the sphere of education seriously changed, despite the financial and economic problems, such as the gap between general and higher education, problems with social and academic mobility, the dominance of the higher education institutions of a humanitarian profile over technical universities, and the system of partnership between business, the state and education is formed. This partnership allows involving private entities to the implementation of public functions [11, pp. 33-37], and is characterized as an effective instrument for sharing projects tasks and risks between the state and private business [1, p. 18].

In modern science, there are studies that allow determining the main trends and direction of the PPP development in education.

So, V.L. Eremin believes that creation and development of institutions of public participation as a way to implement PPP in the field of education leads to the appearance of steering, public, managers and other councils and trustee boards in educational institutions. Interaction between the state, business, public organizations and educational institutions plays a major role in the development and improvement of the content of curricula, standards, and programs for raising professional skill and professional retraining. The implementation of the term papers and diploma works takes place with direct participation of representatives of business and the state or with the orientation to a specific customer from potential employers representing the state-owned or private industries. Grants in the form of funding specific fields allow developing particular directions of research activities.

It is worth mentioning the creation of alumni associations - public institutions, which are voluntary public self-governing organizations. Alumni associations as a mechanism of PPP belong to the most promising areas of interaction of the state, educational institution, and public and private structures [8].

E.A. Dmitrieva proposes three main directions of interaction, which are possible in this area.

First, this is economic support of higher educational establishments, which includes the development of the material and technical base, the financial support of students, young researchers and faculty in the form of grants, nominal scholarships and various benefits, as well as organization of business games in the universities and the creation of endowment funds [6].

Second, this is managing the content of the educational process, which relates to the joint development of curricula and standards, organization of conferences and round tables, student practices, involvement of highly qualified practitioners in teaching individual disciplines and conducting state qualifying examinations, and also the joint development of the programs for the targeted training of personnel and professional retraining.

Third, PPP in the field of R\&D activity that includes implementation of joint fundamental and applied research projects, construction and equipping of laboratories and research centers, as well as opening of the profile departments at the enterprises and organizations [7]. 
Among these directions of the PPP development, the creation of business incubators and technology parks based on higher educational establishment and endowment funds are the most promising, because they allow attracting additional financial resources [3].

Assigning the endowment funds, alumni associations, boards of trustees, and grants to the forms of PPP is a debatable issue [2].

D.N. Efremov believes that the concession agreements referred to the objects of education play an important role in such a partnership. A private partner (hereinafter - PP) takes the obligation to create and/or reconstruct for its account the property that is determined by this agreement, which belongs or will be the issue of the state. The state takes a responsibility to grant the PP for the period defined in the agreement, the right of possession and use of the object of the concession agreement for the implementation of the said (educational) activity.

The researcher introduces the concept of the life cycle contract in education. The state partner (hereinafter - SP) for its account and using its own materials builds the facility and exploits it during the entire calculated period of exploitation (life cycle), implementing management, repair, care and maintenance. Since the start of the operation, it makes payments for the project from the budget of the corresponding level. Herewith, the SP payments may include the PP services for providing the facility for use, or for the educational services that are provided through such a facility (teaching in school or higher educational establishment).

D.N. Efremov believes that the mixed PPP agreements in education allow combining different types of contracts. For example, a contract that includes performance of works the construction (design, repair, expansion, etc.) of the education facilities of the PP, or a lease contract, in which the PP receives fixed assets on lease terms for a certain period. The PP, with the use of its own funds and with the consent of the lessor, may improve and have the right to recover the cost of these improvements to be made by the SP.

Thus, when addressing the historical experience and determining the basic forms of interaction of the economic systems, the state and the sphere of education, it can be noted that public-private partnership allows attracting missing means for modernization of the material and technical base of education, and eliminate the shortage of resources, necessary for the modernization.

For the state, the use of the PPP mechanisms in the field of education, reduces the load on budgets of all levels, and allow receiving those competencies that it does not have enough. One of the characteristic features of the PPP relations is considered to be more active involvement of the private investor in the formation and discussion of the terms of the future partnership agreements and attraction to cooperation on the basis of balance of private and public interests.

\section{References}

1. A. I. Avrus, The history of Russian universities: essays (Social Science Foundation, Moscow, 2001)

2. A. V. Belitskaya, Yurist, 5 (2014)

3. A. V. Belitskaya, Business Law - Appendix: Effective Business and Technical Law in Russia and Abroad, 18 (2010)

4. S. Yu. Vitte, Memories in 3 volumes (Znaniye, Moscow, 1960)

5. K. T. Galkin, Higher education and training of scientific social workers in the USSR (Sovetskaya Nauka, Moscow, 1958)

6. E. A. Dmitrieva, Development of public-private partnership in the sphere of higher professional education (www.econ.msu.ru/cmt2/lib/a/2094/file/DmitrievaEA.pdf) 
7. E. A. Dmitrieva, I. N. Molchanov, Voprosy Upravleniya, 4 (2017)

8. V. L. Yeremin, Public-private partnership in education (http://nsa-msu.ru/ncd-1-9535/news_publications.html)

9. D. N. Yefremov, Economic Journal, 25 (2012)

10. I. V. Zakharov, E. S. Lyakhovich, The mission of university in the European culture (Novoye Tycyacheletiye, Moscow, 1994)

11. Ministry of Finance, 1802-1902: Anniversary reissue by 2002 (St. Petersburg, 2002)

12. V. I. Naletov, IX Derzhavin Readings (Tambov, 2004)

13. Yu. P. Orlovskiy, Constitutional guarantees of the right to education in the USSR (Nauka, Moscow, 1986)

14. S. N. Selive, Public-private partnership in innovative systems (Institute of Economics of RAS, Moscow, 2010)

15. E. A. Semenova, Analytical reviews of RISI, 17, 4 (2007)

16. E. A. Fomina, History of science and technology in the modern system of knowledge: Sixth Annual Lifetime Conference of the Department of the History of Science and Technology, February 8, 2016 (UMC UPI, Yekaterinburg, 2016) 